\title{
Waiting in pain: a systematic investigation into the provision of persistent pain services in Australia
}

\section{Malcolm N Hogg MB BS, GrDip(PM) FFPANZCA, Head of Pain Services, and Vice President}

Stephen Gibson BBSc, PhD, Deputy Director, ${ }^{3}$ and Immediate Past President

Amal Helou BHIthSc(Nursing) MM(PM) Nurse Practitioner

Jacklyn DeGabriele BHlthSc(Nursing), GrDip(Midwifery) Acute Pain Nurse

Michael J Farrell BAppSc(Phty). $\mathrm{MSc}$ (Gerontology), PhD Senior Research Fellow

1 Department of Anaesthesia and Pain Management, Royal Melbourne Hospital, Melbourne, VIC

2 Australian Pain Society, Sydney, NSW.

3 National Ageing Research Institute, Melbourne, VIC 4 Pain Management Unit,

Royal Prince Alfred

Hospital, Sydney, NSW.

5 Royal Women's Hospital, Melbourne, VIC.

6 Florey Neurosciences Institute, Melbourne, VIC

malcolm.hogg@ mh.org.au

MJA 2012; 196: 386-390 doi: 10.5694/mjal2.10140

Editorial p 372

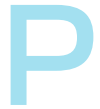

ersistent (or chronic) pain will afflict one in five Australians during their lifetime ${ }^{1}$ and is estimated to cost the Australian economy \$34 billion per annum. ${ }^{2}$ Chronic pain has significant effects on a person's physical and psychological wellbeing, with poor fitness, high rates of psychological distress including suicidality, ${ }^{3}$ impaired work performance, ${ }^{4}$ and high use of health care services. ${ }^{5,6}$ Specialised assessment and treatment processes, including an interdisciplinary team approach and group pain management programs are an established standard of care. ${ }^{7}$

Substantial evidence exists for both the efficacy and effectiveness of cognitive behaviour therapy within a pain clinic environment, ${ }^{8,9}$ with consistent improvements in pain experience and interference, psychological wellbeing and physical functioning. Similarly, early cognitive, ${ }^{10}$ physical $^{11}$ or pharmacological ${ }^{12}$ interventions have been shown to reduce the frequency and severity of some persistent pain states. Consistent with this, a systematic review of the influence of excessive waiting times for access to appropriate pain management found evidence of poorer outcomes in terms of patient quality of life and psychological wellbeing for people waiting up to 6 months for assessment by a pain management service. ${ }^{13}$

Being aware of disparate waiting times across the country and within regions, the Australian Pain Society (APS), a chapter of the International Association for the Study of Pain (IASP), initiated this Waiting in Pain project to better define the current status of service provision for people with persistent pain in Australia. The project's particular focus was on waiting times for clinic access and the availability of allied-health-professional-based group pain management programs (PMP).

\begin{abstract}
Abstrac
Objectives: To document and describe outpatient persistent pain management services in Australia.
\end{abstract}

Design, participants and setting: Systematic survey conducted between 1 December 2008 and 31 January 2010 of 57 services providing outpatient care to adult clients with persistent pain, plus five specialised paediatric services throughout Australia.

Main outcome measures: Service structure, including funding processes; activity, including client numbers, access to specialised services (inpatient care, pain relief interventions); waiting times; and use of allied-health-professionalbased pain management programs.

Results: Of 68 services identified, 57 participated in the study. The median waiting time from referral receipt to initial clinical assessment for a publicly funded outpatient adult pain management service was 150 days, compared with 38.5 days for a privately funded service $(P<0.05)$. There was substantial variability among providers in range of services offered, including provision and duration of allied-health pain management programs. The level of service provision for children and rural patients is notably lower than that reported for urban adult constituents.

Conclusions: Persistent pain management services are currently unable to meet service requirements adequately, and waiting times are more prolonged for publicly funded than privately funded services. Greater service provision is required in rural areas and for children.

\section{Methods}

The Waiting in Pain project involved a structured interview-based survey conducted between 1 December 2008 and 31 January 2010 that included a range of quantitative questions as well as qualitative, open-ended questions (interview questions available on request). National specialist pain management services were identified from an existing APS directory, internet searches, and by interview of clinical leaders in each region. One or both of two researchers performed telephone or in-person interviews with service directors (medical, nursing and/or allied-health staff), with participants provided with the questionnaires before the interview and with telephone or email follow-up as required. Services were asked to participate if they managed more than 100 clients per annum and if they gave consent for data collection. In addition, services focused on persistent pain management in children were invited to participate.

The Waiting in Pain project focused on services providing outpatient care for persistent and chronic pain. Core (quantitative) questions addressed service structure, including links to hospital-based acute pain services, numbers of referrals and initial consultations per annum, waiting time from receipt of referral to initial assessment, numbers of medical staff, including specialist training positions, number of research projects, barriers to service delivery, and the availability and hours of a group pain management program. When calculating comparable numbers of referrals seen per effective full-time (EFT) medical staff member, we did not include psychiatry staff because of their inconsistent availability and role of providing secondary consultation liaison activity rather than initial medical assessments.

Quality control included the identification of missing data entries requiring follow-up and the calculation of frequency distributions to identify values beyond the range of expected values. The source of data used by respondents to answer questions was also recorded, to assess quality by asking if the answer had been 
1 Data on persistent pain management services relative to the Australian adult population, state, region, type of service, funding and use of pain management programs (PMPs)

\begin{tabular}{|c|c|c|c|c|c|c|c|c|c|c|c|}
\hline \multirow[b]{2}{*}{$\begin{array}{l}\text { State or } \\
\text { region }\end{array}$} & \multirow[b]{2}{*}{$\begin{array}{l}\text { Adult } \\
\text { population* }\end{array}$} & \multirow{2}{*}{$\begin{array}{l}\text { Patients seen by } \\
\text { pain management } \\
\text { services }\end{array}$} & \multirow{2}{*}{$\begin{array}{l}\text { Total pain } \\
\text { management } \\
\text { services }\end{array}$} & \multicolumn{4}{|c|}{$\begin{array}{l}\text { International Association for the Study } \\
\text { of Pain classification level }{ }^{\dagger}\end{array}$} & \multicolumn{3}{|c|}{ Funding } & \multirow{2}{*}{$\begin{array}{c}\text { Pain } \\
\text { management } \\
\text { services with } \\
\text { PMPs }\end{array}$} \\
\hline & & & & 1 & 2 & 3 & 4 & $\begin{array}{l}>90 \% \\
\text { Public }\end{array}$ & $\begin{array}{l}>90 \% \\
\text { Private }\end{array}$ & Combined & \\
\hline National & 17690281 & 31779 (0.180\%) & 57 & $26(46 \%)$ & 19 (33\%) & $9(16 \%)$ & $3(5 \%)$ & $26(46 \%)$ & $18(32 \%)$ & $13(23 \%)$ & $42(74 \%)$ \\
\hline SA & 1331103 & $2418(0.182 \%)$ & $4(7 \%)$ & $2(50 \%)$ & $1(25 \%)$ & $1(25 \%)$ & 0 & $2(50 \%)$ & $1(25 \%)$ & $1(25 \%)$ & $2(50 \%)$ \\
\hline Vic & 4418814 & $7393(0.167 \%)$ & $16(28 \%)$ & $5(31 \%)$ & $7(44 \%)$ & $3(19 \%)$ & $1(6 \%)$ & $6(38 \%)$ & $4(25 \%)$ & $6(38 \%)$ & $10(63 \%)$ \\
\hline Tas & 405048 & $1100(0.272 \%)$ & $2(4 \%)$ & $1(50 \%)$ & 0 & $1(50 \%)$ & 0 & $1(50 \%)$ & $1(50 \%)$ & 0 & $1(50 \%)$ \\
\hline NSW & 5756530 & $8348(0.145 \%)$ & 17 (30\%) & 11 (65\%) & $4(24 \%)$ & $2(12 \%)$ & 0 & $9(53 \%)$ & $4(24 \%)$ & $4(24 \%)$ & $14(82 \%)$ \\
\hline ACT & 286171 & 1427 (0.499\%) & $3(5 \%)$ & $2(67 \%)$ & $1(33 \%)$ & 0 & 0 & $1(33 \%)$ & $2(68 \%)$ & 0 & $3(100 \%)$ \\
\hline Qld & 3520239 & 2772 (0.079\%) & $8(14 \%)$ & $2(25 \%)$ & $4(50 \%)$ & $1(13 \%)$ & $1(13 \%)$ & $3(38 \%)$ & $3(38 \%)$ & $2(25 \%)$ & $6(75 \%)$ \\
\hline NT & 171991 & $321(0.187 \%)$ & $2(4 \%)$ & 0 & $1(50 \%)$ & 0 & $1(50 \%)$ & $1(50 \%)$ & $1(50 \%)$ & 0 & $2(100 \%)$ \\
\hline WA & 1798369 & 3400 (0.189\%) & $5(9 \%)$ & $3(60 \%)$ & $1(20 \%)$ & $1(20 \%)$ & 0 & $3(60 \%)$ & $2(40 \%)$ & 0 & $4(80 \%)$ \\
\hline \multicolumn{12}{|l|}{ Region $^{\ddagger}$} \\
\hline Urban & 13687640 & 23310 (0.170\%)* & $47(82.5 \%)$ & $24(51 \%)$ & $14(25 \%)$ & $6(13 \%)$ & $3(6 \%)$ & $22(47 \%)$ & $17(36 \%)$ & $8(17 \%)$ & $33(70 \%)$ \\
\hline Provincial & 8187280 & 3649 (0.045\%)* & 10 (17.5\%) & $2(20 \%)$ & $5(50 \%)$ & $3(30 \%)$ & 0 & $4(40 \%)$ & $1(10 \%)$ & $5(50 \%)$ & 9 (90\%) \\
\hline
\end{tabular}

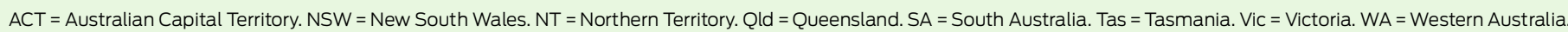

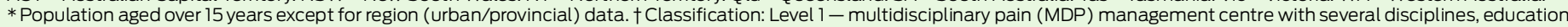

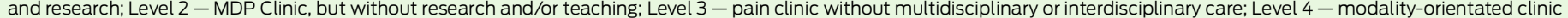
using a single practice or pain management method. łUrban refers to population of capital cities, and provincial refers to population outside capital cities.

produced from an organisation's electronic data capture, service list or data collection, or informed estimation by key personnel.

Services were classified according to region (state; urban [capital city] or provincial [outside capital cities]), funding processes (public [>90\% state or federal]; private [>90\% private health insurance or compensable patients]; or combination [between $10 \%$ and $90 \%$ public or private funding]), and IASP classification at the time we conducted the project, as follows:

- Level 1 - multidisciplinary pain (MDP) management centre with several disciplines, education and research;

- Level 2 - MDP clinic but without research and/or teaching;

- Level 3 - Pain clinic without multi or interdisciplinary care;

- Level 4 - Modality orientated clinic that uses a single practice or pain management method (subsequent revisions to these criteria have merged Levels 3 and 4 into a pain practice grouping). ${ }^{14}$

\section{Statistical analyses}

Data collected were collated on a Microsoft Excel (Microsoft Corporation, Redmond, Wash, USA) spreadsheet and further analysed using SPSS Version 18.0.0 (SPSS Inc, Chicago, Ill, USA). Preliminary analysis involved calculating descriptive statistics for each of the core questions using frequencies, medians, and means, depending on the measurement attributes of the responses.

Statistical tests were used to assess effects associated with structural factors on waiting times, number of patients attending clinics, and clinic IASP classification. The structural factors were clinic attributes likely to influence service provision, including funding source (private and public funding mix as categories or proportions), geographic location (urban or provincial) and service model (clinic IASP classifications). Analyses of variance and $t$ tests were used to assess the effects of structural factors on patient numbers in relation to EFT medical staff. We used Mann-Whitney $U$ or Kruskal-Wallis tests to test for the effects of structural factors on waiting times because of the skewed distribution of waiting times. $\chi^{2}$ tests were used to assess for differences in the frequency of IASP classifications according to clinic attributes. Pearson correlation coefficients were calculated to assess shared variance between proportional levels of funding (\% private) among services with combined sources of funding and waiting times. Findings with a probability of $P<0.05$ were considered statistically significant.

\section{Ethics approval}

The project was approved by the Human Research Ethics Committee of Melbourne Health (HREC approval number 2008: 119).

\section{Results}

Sixty-eight adult persistent pain services were identified and contacted. Two adult services were excluded (because they had fewer than 100 referrals per annum), and six services declined to participate (citing time requirements or service confidentiality), while three services did not respond. Fifty-seven (84\%) of those contacted agreed to participate, and their directors were interviewed over the 14 months from 1 December 2008 to 31 January 2010.

Data capture at the 57 services was organisation-electronic at 27 , by service list or data collection at 21 and by informed estimation by key personnel at nine. Publicly funded services were more likely to be classified as MDP centres (IASP Level 1) than privately funded services $\left(\chi^{2}(3)=16.5, P<0.001\right)$.

Twenty-two of the 57 participating services (39\%) were associated with an acute pain service (PS), five (9\%) services incorporated an acute PS, with the remaining 30 (53\%) having no affiliation with an acute PS. Twenty-three 
2 Waiting times for initial assessment for a non-urgent adult outpatient referral to a persistent pain service

\begin{tabular}{lcccc} 
& & \multicolumn{3}{c}{ Waiting time (days) } \\
\cline { 2 - 5 } & Total pain management services & Median & Range & Interquartile range \\
\hline National & 57 & 103 & $10-575$ & $44-210$ \\
SA & 4 & 180 & $42-420$ & $69-366$ \\
Vic & 16 & 112.3 & $25-370$ & $63-173$ \\
Tas & 2 & 120 & $30-210$ & \\
NSW & 17 & 70 & $14-365$ & $43-230$ \\
ACT & 3 & 70 & $10-241$ & \\
Qld & 8 & 105 & $30-575$ & $38-343$ \\
NT & 2 & 106 & $14-120$ & \\
WA & 5 & 56 & $21-365$ & $33-258$ \\
\hline Region* & & & & \\
\hline Urban & 47 & 103 & $14-575$ & $42-210$ \\
Provincial & 10 & 120 & $21-365$ & $55-204$ \\
\hline Funding & & & & \\
\hline Public $>$ 90\% & 26 & 150 & $34-575$ & $68-281$ \\
Private $>$ 90\% & 18 & 38.5 & $10-120$ & $24-75$ \\
Combination & 13 & 160 & $21-420$ & $66-340$ \\
\hline International Association for the Study of Pain classification ${ }^{\dagger}$ & & & \\
\hline Level 1 & 26 & 150 & $56-420$ & $68-250$ \\
Level 2 & 19 & 90 & $10-575$ & $25-210$ \\
Level 3 & 9 & 45 & $14-365$ & $30-135$ \\
Level 4 & 3 & 30 & $14-90$ & \\
\hline ACT & 9 A & & & \\
\hline
\end{tabular}

ACT = Australian Capital Territory. NSW = New South Wales. NT = Northern Territory. Qld = Queensland. SA = South Australia. Tas = Tasmania. Vic $=$ Victoria. WA $=$ Western Australia.

* Urban refers to population of capital cities, and provincial refers to population outside capital cities. † Classification: Level 1 multidisciplinary pain (MDP) management centre with several disciplines, education and research; Level 2 - MDP Clinic, but without research and/or teaching; Level 3 - pain clinic without multidisciplinary or interdisciplinary care; Level 4 - modalityorientated clinic using a single practice or pain management method.

3 Waiting time for access to the 57 participating adult persistent pain management services in Australia

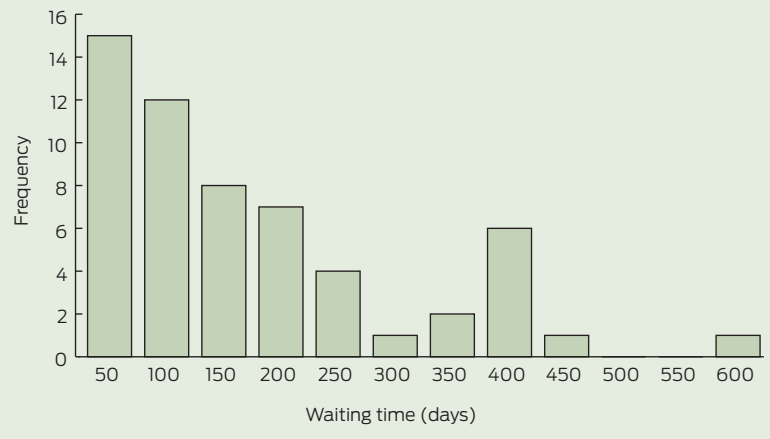

services (40\%) did not have access to inpatient care. Persistent pain management service provision by state, region, type of service, funding and use of pain management programs (PMPs) is described in Box 1.

\section{Waiting times}

Median, ranges, and interquartile ranges for waiting time information based on region, funding and IASP classifications are presented in Box 2. Box 3 shows the frequency distribu- tion of waiting times and demonstrates that the distribution was skewed (Shapiro-Wilk statistic, 0.845; $P<0.001)$. The waiting time for initial assessment for a new persistent pain outpatient referral was less for privately funded services (mean rank, 14.7) than publicly funded (mean rank, 35.7) or combination funded services (mean rank, 35.5; KruskalWallis $\left.\mathrm{H}_{(d f, 2)}=19.5 ; P<0.001\right)$.

Nationally, waiting times did not differ between urban and provincial centres (Mann-Whitney $\mathrm{U}=252.5$; $P=0.7$ ), or based on IASP classification $\left(\mathrm{H}_{(d f, 3)}=7.7, P=0.053\right)$. No correlation was found in relation to percentage of public funding and waiting times for the 13 services with a combination of public and private funding (Pearson correlation coefficient $r=0.28$; $P=0.3$ ). For the 42 services offering an allied-healthprofessional-based PMP, the median waiting time was 112.5 days (interquartile range, 56-218 days) compared with 70 days (interquartile range, 30-120 days) for the 12 services without a PMP $(\mathrm{U}=385 ; P=0.2)$.
A triage process for the management of urgent referrals, commonly identified as patients with cancer pain, acute neuropathic pain states or high levels of distress, was identified by 47 of the 57 services ( $83 \%$ ). Waiting times for these referrals were less than 4 weeks.

\section{Service activity and medical staff levels}

Estimates of new outpatient clients assessed annually per reported EFT medical staff member ranged from 299 to 441 between states and from 345 to 365 between urban and provincial services. Mean new patients seen per EFT medical staff member was higher for modality-orientated clinics (IASP Level 4, 708 patients; SD, 438 patients) than pain clinics (IASP Level 3, 402 patients; SD, 307 patients), MDP clinics (IASP Level 2, 387 patients; SD, 264 patients) and MDP centres (IASP Level 1, 260 patients; SD, 167 patients; $F(3,56)=3.7$; $P<0.02)$. The number of new patients seen per EFT medical staff member was higher for privately funded services (498 patients; SD, 310 patients) compared with publicly funded services (290 patients; SD, 219 patients) or combination (240 patients; SD, 128; $F(2,56)=5.8, P<0.005)$.

\section{Allied-health-professional-based pain management programs}

Forty-two (74\%) of the 57 services offered a group PMP, 39 of which were offered by IASP Level 1 or 2 services, while nine PMPs were offered by services classified as more than $90 \%$ privately funded (involving 16\% of services). An additional five services (9\%) offered access to individual allied-health therapy. Although the mean total time involved in a group PMP was 69 hours, there was a bimodal distribution with 24 programs involving more than 60 hours. We estimated that 3628 clients per annum started a PMP, with 1335 of these being in a privately funded service.

\section{Interventional procedures}

Nationally, an estimated 22300 minor (eg, epidural steroid injection) and 380 major (eg, spinal cord stimulation) pain-reduction procedures were performed by 50 of the 57 participating services. We found no differences 
between mean numbers of procedures per service based on funding sources because of the large variability between services (publicly funded, 249.7 procedures; SD, 311; range, 0-1070; privately funded, 591.4 procedures; SD, 1061; range, 0-4530; combined funding sources 434.1 procedures; SD 499; range, 0-1720).

\section{Additional subspecialty services}

A range of subspecialty services were identified among the 57 participating adult persistent pain services, including combined addiction and pain service (four services), older person clinic (three), palliative medicine (three), acupuncture (two), dental (two), and spinal (two). Three services identified a funded outreach program whereby their services were available to regional areas, either by telemedicine or visiting multidisciplinary teams.

\section{Education and research}

Twenty-five funded pain medicine specialist training positions were reported in 19 services, one of which was in a provincial area. No funded positions were reported in services identified as more than $90 \%$ privately funded. One hundred and fifty-five research projects were identified, 52 of which were being undertaken in nine privately funded services.

\section{Paediatric persistent pain services}

Three established paediatric persistent pain services were identified (two in New South Wales, one in Victoria), while two services reported having a specialist paediatric service associated with an established adult service (one each in NSW and Victoria). All three established paediatric services were multidisciplinary in nature, associated with tertiary children's hospitals, and assessed approximately 315 outpatients per year with a waiting time for initial access of 60 days. In Queensland, South Australia and Western Australia, specialised paediatric pain services were in a development or early implementation stage.

\section{Discussion}

The Waiting in Pain project provides a snapshot of current specialist pain management services throughout
Australia. We have shown a range of service provision characteristics and waiting times, possibly reflecting their stages of development, location, or funding processes. The lack of both national benchmarks for quality and access to multidisciplinary care for patients suffering persistent pain are recognised as problems and are development goals in the National Pain Strategy. ${ }^{7}$ Our results on waiting times are similar to those reported from Canada, where an estimated $0.15 \%$ of the population used persistent pain services (incorporating paediatric services) each year. ${ }^{15} \mathrm{~A}$ subsequent analysis of a sample of patients on waiting lists of Canadian pain facilities showed that most report severe pain (scored $>7 / 10$ in severity) with high levels of depression and suicidality. ${ }^{16}$

Based on our data and the Australian Bureau of Statistics June 2009 estimate of population (17 690281 people aged $>15$ years) for service activity estimations, $0.18 \%$ of the population were assessed by an adult persistent pain service. ${ }^{17}$ Activity rates per head of population are lower for non-capital city services, although many patients from these areas will travel to cities for access to specialist care. A telephone survey of an Australian sample population found high levels of pain-related disability in $27 \%$ of the $22 \%$ of their participants who reported chronic pain. ${ }^{5}$ Higher rates of disability were associated with greater use of health care resources and medications, suggesting that about $5 \%$ of the population could potentially benefit from access to MDP management services.

Our discussions with directors of specialist paediatric pain services revealed difficulties establishing these services, with subsequent limited capacity. When considering the services of the two states with the largest estimated populations of people aged less than 15 years, ${ }^{17}$ we estimate that new persistent pain assessments are being made for $0.01 \%-0.02 \%$ of this population; this is consistent with the Canadian assessment of underdeveloped services for this population. ${ }^{18} \mathrm{~A}$ moderate waiting time in the setting of low capacity reflects a limited referral base, despite chronic pain being reported as common in children and adolescents. ${ }^{19}$ Given the strong evidence of multidisciplinary care in reducing pain and disability in children with persistent pain, ${ }^{20}$ improving access by developing staff and services throughout Australia needs to be a priority.

At the other end of the population spectrum, older people are known to have a higher prevalence of persistent pain, ${ }^{21}$ yet only a small number of persistent pain services have programs designed for older people; demand for such programs may be expected to increase with the ageing of the population.

A consequence of poor geographical access and prolonged waiting times is a reluctance of general practitioners to refer patients for specialist services. In an analysis of referral patterns of 37 family practitioners in Ontario, the three most frequently cited reasons for referring patients to a pain service were requests for injections, desire for specialist expertise and concern about opioids, whereas long waiting lists, patient preference for other treatments and distance from pain services were the three most prevalent barriers to referral. ${ }^{22}$ Few of the existing pain services described a process for evaluating rural clients, although this practice may increase following the federal government's 2011 Medicare-based initiative to support telemedicine. ${ }^{23}$

Participation and data quality can be limitations of surveys of this type. Although we had a high rate of participation among the multidisciplinary services we identified, we did not assess the significant services provided by single specialists, GPs with an interest in pain management, and other speciality areas that may provide pain management (eg, rheumatology). In terms of data quality, fewer than half of the persistent pain management services we surveyed had data that were systematically and electronically captured by their supporting organisation; data collection may improve if waiting times for outpatient services are part of mandatory reporting data within activity-based funding agreements. In addition, our questionnaire was not assessed for reliability or validity. Since we completed this project, a number of developments have targeted access issues 
at a local level. These include the plan initiated by the Queensland Government to develop regional pain management services, the introduction of a "preclinic" self-management education program by the Freemantle pain management service ${ }^{24}$ and a process of engagement with communitybased services initiated in the Hunter region of NSW, with a subsequent reduction in waiting times for MDP service assessment. ${ }^{25}$ Given that excessive waiting in pain is associated with worsening health, that early access to pain management improves outcomes, and that the Australian population is ageing, greater national political support to improve access to pain management services is required.

Acknowledgements: We, on behalf of the APS, thank all the participating services. Jacklyn DeGabriele's participation was supported by a grant from the APS and the Department of Anaesthesia and Pain Management, Royal Melbourne Hospital.

Competing interests: Malcolm Hogg and his employer have received honoraria for GP education services and advisory board participation from Mundipharma and Janssen-Cilag. The APS receives sponsorship for its Annual Scientific Meeting and Research Scholarship Program from a range of pharmaceutical and medical device companies. These include Mundipharma, Janssen-Cilag. Pfizer Australia, and Medtronic Australasia.

Received 23 Jan 2012, accepted 5 Mar 2012

1 Blyth FM, March LM, Brnabic AJM, Cousin MJ. Chronic pain in Australia: a prevalence study. Pain 2001; 89: 127-134.

2 The high price of pain: the economic impact of persistent pain in Australia in 2007. Report by Access Economics Pty Limited for MBF Foundation in collaboration with the University of Sydney Pain Management Research Institute. November 2007. http://www.bupa.com.au/ staticfiles/BupaP3/Health\%20and\%20 Wellness/MediaFiles/PDFs/MBF_Foundation_ the price of pain.pdf (accessed Nov 2011).
3 Yang NK, Crane C. Suicidality in chronic pain: a review of the prevalence, risk factors and psychological links. Psychol Med 2006; 36 : 575-586.

4 Van Leeuwen MT, Blyth FM, Nicholas MK, Cousins MJ. Chronic pain and reduced work effectiveness: the hidden costs to Australian employers. Eur J Pain 2006; 10: 161-166.

5 Blyth FM, March LM, Nicholas MK, Cousins MJ. Chronic pain related disability and use of analgesia and health services in a Sydney community. Med J Aust 2003; 179: 84-87.

6 Blyth FM, March LM, Brnabic AJ, Cousins MJ. Chronic pain and frequent use of health care. Pain 2004; 111: 51-58.

7 National Pain Summit initiative. National Pain Strategy. Pain management for all Australians. March 2010. http://www.anzspm.org.au/c/ anzspm?a=sendfile\&ft=p\&fid $=$ $1320268502 \&$ sid $=$ (accessed Nov 2011).

8 Morley S, Williams A, Hussain S. Estimating the effectiveness of cognitive behavioural therapy in the clinic: evaluation of a CBT informed pain management programme. Pain 2008; 137: $670-680$

9 Eccleston C, Williams AC, Morley S. Psychologica therapies for the management of chronic pain (excluding headache) in adults. Cochrane Database Syst Rev 2009; (2): CD007407.

10 Linton SJ, Anderson T. Can chronic disability be prevented? A randomised trial of a cognitivebehavoural intervention and two forms of information for spinal pain patients. Spine 2000; 25: 2825-2831.

11 Cedraschi C, Desmeules J, Rapiti E, et al. Fibromyalgia: a randomised controlled trial of a treatment programme based on self management. Ann Rheum Dis 2004; 63 : 290-296.

12 Bowsher D. Factors influencing the feature of postherpetic neuralgia and outcome when treated with tricyclics. Eur J Pain 2003; 7: 1-7.

13 Lynch ME, Campbell F, Clark AJ, et al. A systematic review of the effect of waiting for treatment for chronic pain. Pain 2008; 136 : 97-116.

14 International Association for the Study of Pain. Recommendations for pain treatment services. http://www.iasp-pain.org/AM/template.cfm? Section=Pain_Treatment_Facilities (accessed Jun 2008).
15 Peng P, Choiniere M, Dion D, et al. Challenges in accessing multidisciplinary pain treatment facilities in Canada. Can J Anaesth 2007; 54 : 977-984.

16 Choiniere M, Dion D, Peng P, et al. The Canadian STOP-PAIN project. Part 1: Who are the patients on the waitlists of multidisciplinary pain treatment facilities? Can J Anaesth 2010; 57: 539-548.

17 Australian Bureau of Statistics, Australian demographic statistics. June quarter 2009. Released 3 Dec, 2009. (ABS Cat No. 3101.1.) http:// www.ausstats.abs.gov.au/Ausstats/ subscriber.nsf/0/FB52766C453652ElCA 25768000196B47/\$File/31010 jun\% 202009.pdf (accessed Feb 2010).

18 Peng P, Stinson JN, Choiniere M, et al. Dedicated multidisciplinary pain management centres for children in Canada: the current status. Can J Anaesth 2007; 54: 985-991.

19 van Dijk A, McGrath PA, Picket, et al. Pain prevalence in nine to 13 year-old school children. Pain Res Manag 2006; 11: 234-240.

20 Palermo TM, Eccleston C, Lewandowski AS, et al. Randomised controlled trials of psychological therapies for the management of chronic pain in children and adolescents: an updated metaanalytic review. Pain 2010; 148: 387-397.

21 Jones G, Macfarlane G. Epidemiology of pain in older persons. In: Gibson S, Weiner D, editors. Pain in older persons: progress in pain research and management. Vol 35. Seattle: IASP Press, 2005: 3-22.

22 Lakha SF, Yegneswaran B, Furlan JC, et al. Referring patients with chronic noncancer pain to pain clinics: survey of Ontario family physicians. Can Fam Physician 2011; 57: el06-ell2.

23 Telehealth - modernising medicine by providing rebates for online consultations. MBS Online. Medicare Benefits Schedule. http://www. mbsonline.gov.au/internet/mbsonline/ publishing.nsf/Content/mbsonline-telehealthlanding.htm (accessed Mar 2012).

24 Davies S, Quintner J, Parsons R, et al. Pre-clinic group education sessions reduce waiting times and costs at public pain medicine units. Pain Med 2011; 12: 59-71.

25 Hayes C, Hodson FJ. A whole person model of care for persistent pain: from conceptual framework to practical application. Pain Med 2011; 12: 1738-1749. 